\title{
Natural Vibration Frequency Definition Of Turbine Blades
}

\author{
Evgeny Malkin* \\ National Technology Initiative Center for Advanced Manufacturing Technologies based on \\ the Institute of Advanced Manufacturing Technologies of Peter the Great St. Petersburg \\ Polytechnic University Polytechnicheskaya, 29, St.Petersburg, 195251, Russia
}

\begin{abstract}
A turbine compressor package is used for pipeline gas transmission. When operating, compressor turbine blades develop vibration, which increases the number of dynamic stress cycles and results in the blade failure. The present study aims to determine the frequency of natural blade vibration and to consider it in the context of the blade repair process. In the first stage of the study, an oscillating contour is developed to generate standing oscillation wave which characteristics are used as experimental data. To process those data, a mathematical model is developed to calculate the blade resonant frequency. Finally, the boundaries of the assured quality area are determined. Blade operation capacity analysis method will allow us to reduce the number of environmentally dangerous experiments.
\end{abstract}

Keywords: energy, turbine compressor, blades, vibration.

\section{Introduction}

\section{Cause analysis of turbine and compressor blades vibration.}

In the process of gas compressor package operation stator and rotor blades of turbines and compressors vibrate, i.e. oscillate mechanically what is the main cause of blade failure. Dynamic stress caused by oscillation creates near-symmetrical, near-alternating stress cycle. Sufficiently high blade vibration frequencies result in rapid accumulation of number of stress cycles and therefore in blade failure, especially if there are some factors of fatigue resistance reduction: corrosive or erosive damages, dints, material defects, structural stress raisers, residual stress in material surface layers etc. $[2 ; 3]$. According to the nature of the factors causing blade vibration, oscillations can be classified into: forced oscillations, stall oscillations and self-oscillations. Forced oscillations depend on certain variables, periodic forces mainly those of gas flow and torsion oscillation of an engine. Stall oscillations are caused by possible non-periodic blade slaps while operating in abnormal modes. Frequency of such oscillations are equal to the first natural frequency of blade oscillation. Selfoscillation is a kind of aeroelasticity phenomenon; it is analogous to so-called bendingtorsional flutter .Self-oscillations occur in the absence of distortions, pulsations or stall.

\footnotetext{
* Corresponding author: cmno1@mail.ru
} 
Accidental or forced deviations of a blade airfoil result in the flow distortion, change its angle of attack and force applied to the airfoil, i.e. blade oscillations can generate periodic force themselves. Direct measurement of blade dynamic stress in an operating turbo-machine (for instance, by strain-gage testing) allows obtaining reliable data, but such procedures are quite difficult and labour-intensive [4]. Therefore, an estimation of probable blade resonance states is necessary. Thus, we have two objectives: to find causes of vibration forces and to determine natural blade oscillation frequencies.

Description and working principle of the turbine compressor package GTK-10-4.

Turbine compressor package GTK-10-4 is designed on the basis of the aeronautical drive NK-16ST and used for pipeline gas transmission [1]. The package is a machine mounted on a reinforced concrete base; the equipment parts of the package are arranged in separate transportable units (Fig. 1) and comprise the following major components: 1. Air-intake chamber 1 used for atmospheric air purification flowing into the axial flow compressor; starter motor 2 (turbo expander, air start unit or electrical starter) used for initial spinning of an axial flow compressor (AC) and a high pressure turbine at the start of the turbine compressor package. 2. Axial compressor 3 used for air supply into combustion chamber (CC) of a gas turbine engine. 3. High pressure turbine (HP turbine) 4 used as an axial compressor drive and mounted on the same shaft. 4. Low pressure turbine (LP turbine) 5 driving a centrifugal natural gas supercharger and constituting a centrifugal gas compressor. 5. Combustion chamber 9 used for fuel gas combustion in air flow and for deriving combustion products having designed parameters (pressure, temperature) at the HP turbine inlet. 6. Starting gas and fuel gas preparation units (10 and 8 respectively) used to clear suction gas from impurities and damp and to prepare gas for further operation in accordance with operation requirements for gas compressor units. 7. Air-based oil cooler 11 used for cooling of lube oil of turbines and supercharger. Besides, each turbine compressor package is provided with basic operational parameters control system, aggregate automatics system, automatic fire fighting system, gas contamination detection system etc.

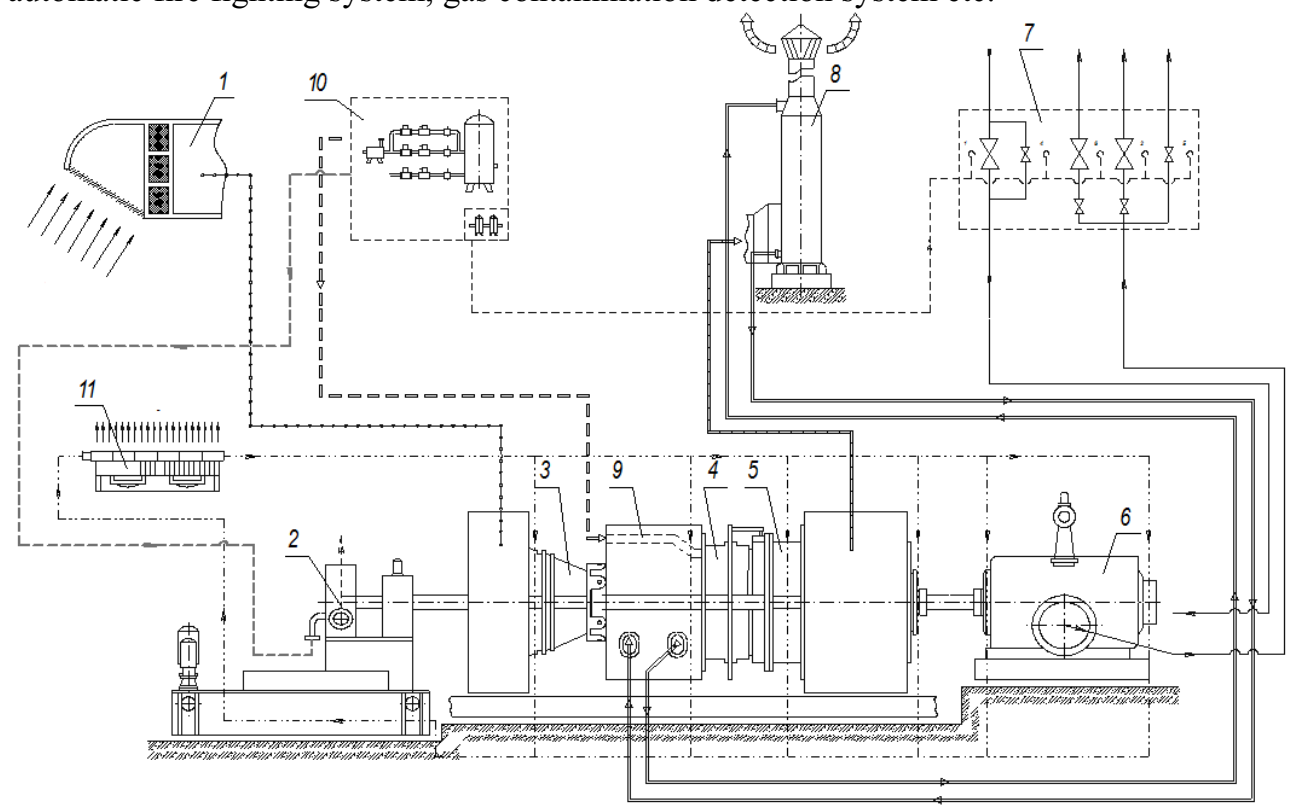

Fig. 1. Schematic structural diagram of a turbine compressor package 
Description of the process "Natural vibration frequency of rotor blades measurement".

The process "Natural vibration frequency of rotor blade measurement" is carried out twice, at the fault detection stage and after blade repair. further we shall consider the addition of natural vibration frequency measurement to the repair process. Measurement process of natural vibration frequency of prevailing form of blade torsion oscillations is shown in Figure 2.

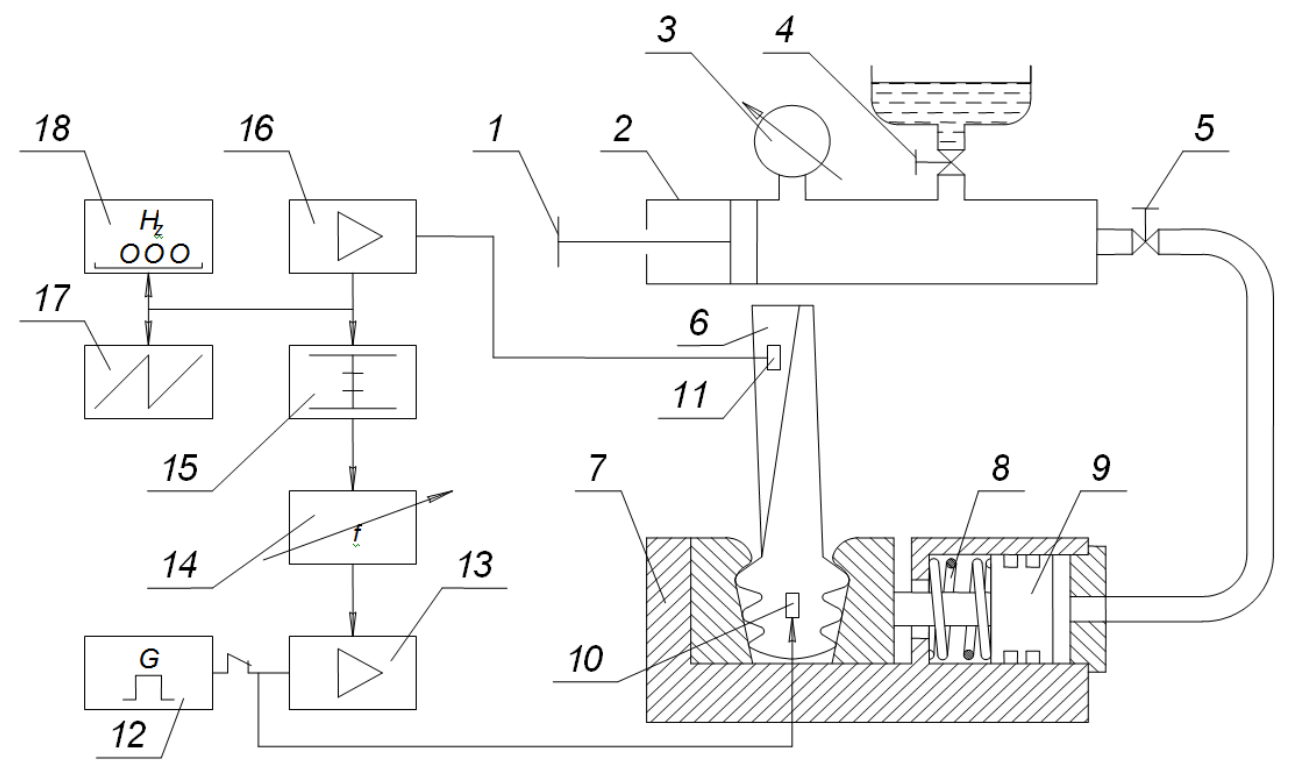

Fig. 2. Procedure of blade natural vibration frequency measurement

For generating standing wave of sample torsion oscillations and defining their frequency a generator is developed, designed as a positive-feedback amplifier. For feedback is obtained using sample 6, phase inverter 14 and mechanic oscillations receiver 11. An examined sample functions as an oscillating contour. Phase inverter allows gradual adjusting of output-toinput voltage ratio within the range of $180^{\circ}$ providing a possibility for self-oscillations optimal mode selection. To record sample oscillations an electromagnetic sensor 10 can be used, which is designed on the base of differential-electromagnetic microphone. For oscillations generating an electrodynamic vibration exciter can be used. Four-pole 15 provides adjust amplifier output to phase inverter output. A blade 6 is fixed in a hydraulic clamping device and sensors 10 and 11 are attached to the blade according to the scheme. Sensor 10 generating mechanic oscillations is attached to the blade whereas impulse generator 12 provides alternating current for the sensor. At the edge of the blade airfoil a sensor 11 receiving mechanic oscillations is attached. Receiving sensor 11 is attached with plasticine, and generating sensor 10 is mounted on a stand using dampers. Stands are fixed on a foam rubber or foam plastic pad. Dampers are used to isolate receiving sensor oscillations from those of generating sensor, so that generator oscillations are related to receiver oscillations only through the sample excluding unwanted oscillation of external sources. Impulse generator is connected electrically to electronic frequency meter 18 measuring frequency within the accuracy of $0.1 \mathrm{~Hz}$. Receiver 11 is connected to the cathoderay oscilloscope 17 through sinusoidal voltage amplifier 16. Generator and amplifier output 13 voltage having a certain frequency is applied to the mechanic oscillation generator 10 which transforms electric oscillation into mechanic oscillation of the vibration generator. Electrodynamic vibration generator generates oscillation of test sample 6 which is received by the receiver 16 transforming mechanic sample oscillation into electric signals. A signal 
of receiving sensor is amplified and applied to the cathode-ray oscilloscope input 17. By gradual adjusting of signal generator frequency, maximal oscillation amplitude is obtained on the oscilloscope display. Using frequency meter blade natural oscillation frequency is defined, whereafter Young's modulus of elasticity $\mathrm{E}$ is determined from formulas.

\section{$2 \quad$ Materials and methods}

Further we are discussing mathematical tools for accurate calculation of boundaries for blades not having any internal defects. Acoustic research methods of material physical and mechanical properties are most promising. They provide an ability to define sample properties without destroying them. Moreover, the measurements are both low-cost and not labour-intensive since an enterprise has already necessary equipment and personnel for using these methods. Further a procedure of blade natural vibration frequency measurement is suggested using an acoustic method. To find a differential equation of blade lateral oscillation in case of heterogeneous distribution of elasticity modulus over its thickness we shall consider elasticity theory equations in Cartesian coordinate system [5]:

$$
\frac{\partial \sigma_{i j}}{\partial x_{i}}=\rho \frac{\partial^{2} U_{j}}{\partial t^{2}},
$$

where $\sigma_{i j}$ stress components;

$\mathrm{U}_{\mathrm{j}}$ displacement vector components;

$\mathrm{x}_{\mathrm{i}}$ coordinates, $\mathrm{i}=1,2,3$.

Stress components $\sigma_{i j}$ are related to deformation components by Hook's law:

$$
\varepsilon_{i j}=\frac{1+v}{E} \sigma_{i j}-\frac{v}{E} \sigma_{i j} \delta_{i j},
$$

where $E=E(x)$ Young's modulus of elasticity;

$\mathrm{x}$ blade thickness coordinate;

$\delta_{i j}$ Kronecker index equal to 1 if $i=j$;

$v$ Poisson's ratio.

Deformation components are related to stress vector components by Cauchy equations:

$$
\varepsilon_{i j}=\frac{1}{2}\left(\frac{\partial U_{i}}{\partial x_{j}}+\frac{\partial U_{j}}{\partial x_{i}}\right),
$$

Further we can use the Kirchhoff hypothesis. In this case

$\sigma_{33}=0 ; \varepsilon_{13}=\varepsilon_{23}=0 ; \mathrm{U}_{3}\left(\mathrm{x}_{1}, \mathrm{x}_{2}, \mathrm{x}_{3}\right)=\mathrm{U}_{3}\left(\mathrm{x}_{1}, \mathrm{x}_{2}, 0\right)=\psi\left(\mathrm{x}_{1}, \mathrm{x}_{2}\right) ; \mathrm{U}_{2}\left(\mathrm{x}_{1}, \mathrm{x}_{2}, \mathrm{x}_{3}\right)=\mathrm{U}_{2}\left(\mathrm{x}_{1}, \mathrm{x}_{2}, 0\right)-$ $\mathrm{x}_{3} \partial \psi / \partial \mathrm{x}_{1}$

$\mathrm{U}_{1}\left(\mathrm{x}_{1}, \mathrm{x}_{2}, \mathrm{x}_{3}\right)=\mathrm{U}_{1}\left(\mathrm{x}_{1}, \mathrm{x}_{2}, 0\right)-\mathrm{x}_{3} \partial \psi / \partial \mathrm{x}_{2}$

whereby as a starting point on $\mathrm{x}_{3}$ axis is considered a crossing point of $\mathrm{x}_{3}$ axis and a neutral plane. If the neutral plane is inextensible $\mathrm{U}_{1}\left(\mathrm{x}_{1}, \mathrm{x}_{2}, 0\right)=\mathrm{U}_{2}\left(\mathrm{x}_{1}, \mathrm{x}_{2}, 0\right)=0$.

We shall integrate (1) with respect to blade section $\mathrm{x} 3$ between $[-\delta, \mathrm{h}-\delta]$, where $\mathrm{h}$ is total blade thickness; $\delta$ is the distance between the neutral plane and the lower surface of the plate. Considering that both blade surfaces are unstressed, i.e.

$$
\begin{aligned}
& \left.\sigma_{i j}\right|_{x_{3}=-\partial, h-\partial}=0 \text {, we obtain } \\
& \frac{\partial N_{11}}{\partial x_{1}}+\frac{\partial N_{12}}{\partial x_{2}}=-S_{\rho} \frac{\partial^{3} \psi}{\partial t^{2} \partial x_{1}} ; \frac{\partial N_{12}}{\partial x_{1}}+\frac{\partial N_{22}}{\partial x_{2}}=-S_{\rho} \frac{\partial^{3} \psi}{\partial t^{2} \partial x_{2}} ; \frac{\partial Q_{11}}{\partial x_{1}}+\frac{\partial Q_{12}}{\partial x_{2}}=-X_{\rho} \frac{\partial^{2} \psi}{\partial t^{2}}, \\
& \text { where }
\end{aligned}
$$




$$
N_{i j}=\int_{-\delta}^{h-\delta} \sigma_{i j} d x_{3} ; Q_{31}=\int_{-\beta}^{h-\beta} \sigma_{3 j} d x_{3} ; X_{\rho}=\int_{-\delta}^{h-\delta} \rho d x_{3} ; S_{\rho}=\int_{-\delta}^{h-\delta} x_{3} \rho d x_{3} .
$$

On multiplying equation (1) by $\mathrm{x}_{3}$ and integrating within the same limits, we obtain

$$
\begin{aligned}
& \frac{\partial M_{11}}{\partial x_{1}}+\frac{\partial M_{12}}{\partial x_{2}}-Q_{31}=-J_{\rho} \frac{\partial^{3} \psi}{\partial t^{2} \partial x_{1}} ; \frac{\partial M_{12}}{\partial x_{1}}+\frac{\partial M_{22}}{\partial x_{2}}-Q_{32}=-J_{\rho} \frac{\partial^{3} \psi}{\partial t^{2} \partial x_{2}} ; \frac{\partial M_{13}}{\partial x_{1}}+\frac{\partial M_{32}}{\partial x_{2}}=S_{\rho} \frac{\partial^{2} \psi}{\partial t^{2}}, \\
& \text { were } M_{i j}=\int_{-\delta}^{h-\delta} x_{3} \sigma_{i j} d x_{3} ; J_{\rho}=\int_{-\delta}^{h-\delta} x_{3}^{2} \rho d x_{3}
\end{aligned}
$$

\section{Results and discussion}

Since we are developing new technique for experimental data processing, we can select those geometrical parameters of test samples which simplify experiment and its analysis (with necessary measurement accuracy remaining). As (6) and (7) show, if a blade has parameters $\mathrm{h}$ along $\mathrm{x}_{3}$ axis and $\mathrm{b}$ along $\mathrm{x}_{2}$ axis are substantially less than parameter 1 along $\mathrm{x} 1$ axis (whereby $h<<b<<l$ ), design ratios are considerably simplified. Indeed, in this case we can assume that all variables in (6) do not depend on $\mathrm{x}_{2}$. Moreover, according to St. Venant's principle, $\sigma_{22}=0$. Thus, the first equation of the system (6) and the third equation of the system (5) are as follows:

$$
\frac{\partial Q_{31}}{\partial x_{1}}=X_{\rho} \frac{\partial^{2} \psi}{\partial t^{2}} ; \frac{\partial M_{11}}{\partial x_{1}}-Q_{31}=-J_{\rho} \frac{\partial^{3} \psi}{\partial t^{2} \partial x_{1}} .
$$

On expressing $\mathrm{Q}_{31}$ from the second equation and inserting it into the first one, we obtain

$$
\frac{\partial^{2} M_{11}}{\partial x_{1}^{2}}-X_{\rho} \frac{\partial^{2} \psi}{\partial t^{2}}+J_{\rho} \frac{\partial^{4} \psi}{\partial t^{2} \partial x_{1}^{2}}=0 \text {. }
$$

Assuming in (2) that $\sigma_{22}=0, \sigma_{33}=0$, and with regard to (4) we have

$$
\sigma_{11}=-E x_{3} \frac{\partial^{2} \psi}{\partial x_{1}^{2}} \text {. }
$$

Using definition $\mathrm{M}_{11}$ from (7), we find

$$
M_{11}=\int_{-\delta}^{h-\delta} x_{3} \sigma_{11} d x_{3}=-J_{E} \frac{\partial^{2} \psi}{\partial x_{1}^{2}}
$$

where

$$
J_{E}=\int_{-\delta}^{h-\delta} x_{3}^{2} E\left(x_{3}\right) d x_{3} .
$$

On inserting (11) into (19) we obtain a fourth-order differential equation for defining displacements $\psi=\psi\left(x_{1}, t\right)$ :

$$
J_{E} \frac{\partial^{4} \psi}{\partial x_{1}^{4}}+X_{\rho} \frac{\partial^{2} \psi}{\partial t^{2}}-J_{\rho} \frac{\partial^{4} \psi}{\partial t^{2} \partial x_{1}^{2}}=0
$$

Thus, the equation (13) presents the law of blade vibration in case of heterogeneous distribution of elasticity modulus over its section. For the selected model of blade geometrical parameters $(\mathrm{h}<<\mathrm{l})$ the third term of the equation (13) has the second order of smallness comparing with the first two terms equivalent to each other. Therefore, when measuring first 
harmonic oscillation parameters, the third term of (13) can be neglected comparing with the first two ones, and the equation takes the following form:

$$
\frac{\partial^{2} \psi}{\partial t^{2}}+a^{2} \frac{\partial^{4} \psi}{\partial x_{1}^{4}}=0
$$

where $a^{2}=J_{E} / X_{\rho}$.

As it follows from (14), oscillation equation for heterogeneous distributed elasticity modulus over a bar section coincides formally with oscillation equation for a constant elasticity modulus over a section. Only coefficient $\mathrm{a}^{2}$ functioning as a reduced parameter is different. It should be noted that the third term in the equation (13) describing blade cross section rotation can play a crucial part in measuring of oscillation harmonic higher than the first one. To solve the equation (14) it should be complemented with boundary conditions following from conditions of blade fixing during measuring procedure. In the present case one blade tip is fixed, and the other is free (Fig. 3). For the convenience of further calculation let us set $x=x_{1}$ and $z=x_{3}$. For the fixed blade tip the boundary conditions consist of zero displacement and bar slope ratio at this point equal to zero:

$$
\psi=0 ; \frac{\partial \psi}{\partial x}=0
$$

Mathematical model of blade oscillation in the case when one blade tip is fixed and the other is free is as follows:

$$
\frac{\partial^{2} \psi}{\partial t^{2}}+a^{2} \frac{\partial^{4} \psi}{\partial x^{4}}=0 ; \psi=0 ; \frac{\partial \psi}{\partial x}=0 ; x=0 ; \frac{\partial^{2} \psi}{\partial x^{2}}=0 ; \frac{\partial^{3} \psi}{\partial x^{3}}=0 ; x=l
$$

Solving the problem (16) using the method of variable separation, we obtain the following characteristic equation:

$$
\cos \mu \operatorname{ch} \mu+1=0, \text { г } \partial e=\sqrt{\frac{\omega}{a}} l .
$$

The characteristic equation has an infinite series of square roots defining blade oscillation natural frequency $\omega$. From (17) we obtain n-th harmonic frequency of blade natural oscillation

$$
\omega_{n}=a\left[\frac{{ }^{\mu} n}{l}\right]^{2}
$$

The mathematical tools described above are very cumbersome and difficult for practical implementation at an enterprise. Therefore, we use only the mathematical model (16) for simpler calculation of blade resonant frequency. 


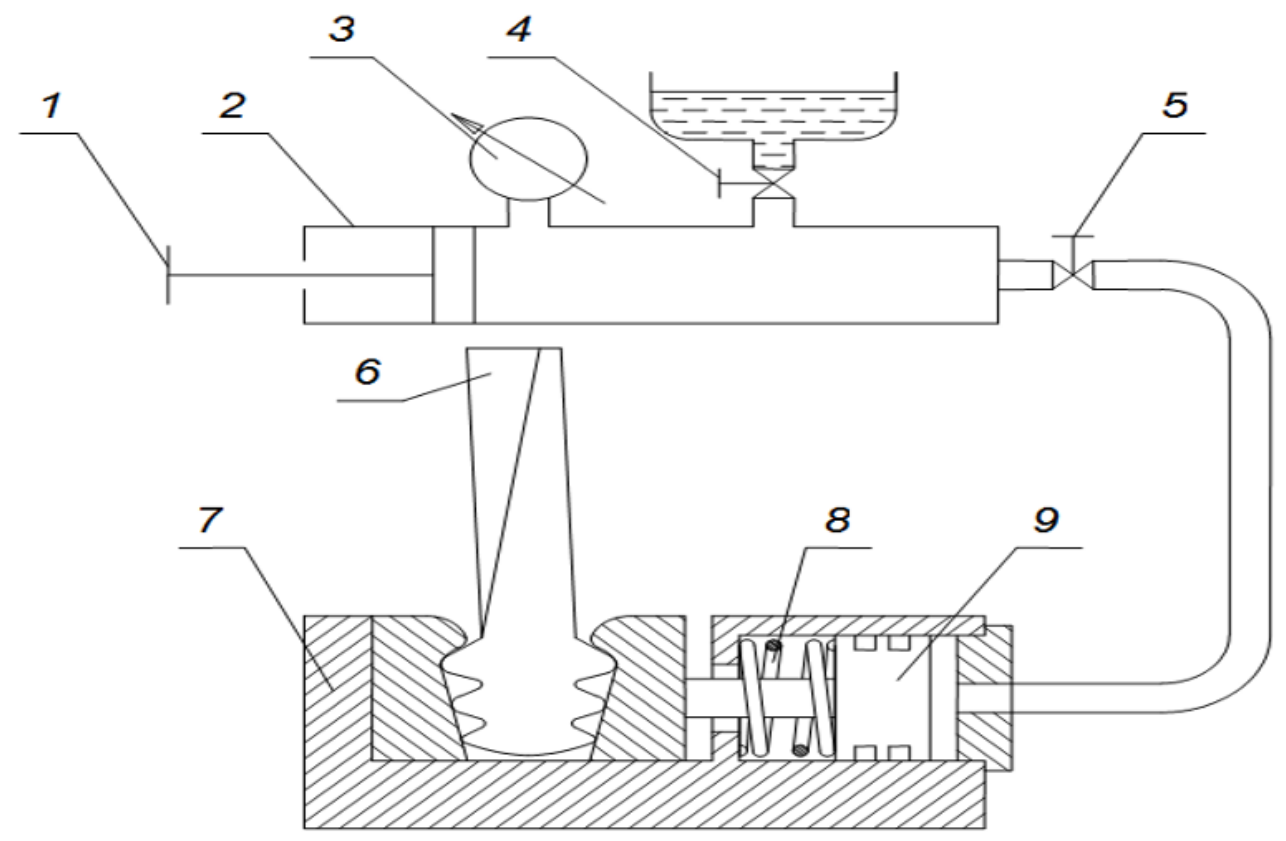

Fig. 3. Scheme of blade fixation for Young's elasticity modulus definition: 1 piston; 2 hydraulic cylinder; 3 manometer; 4, 5 valves; 6 blade; 7 hydraulic clamping device; 8 return spring; 9 actuating piston.

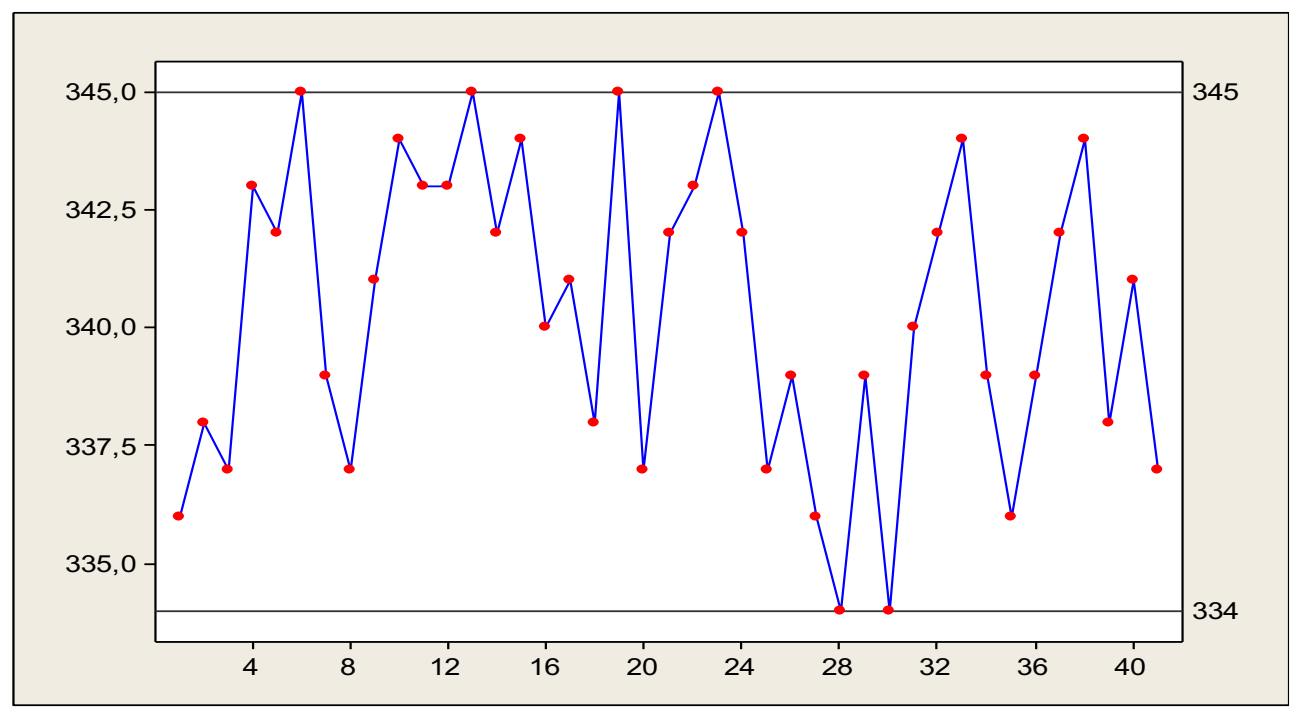

Fig 4. Results distribution chart

Using the technique described above fourth stage blade resonant frequencies of GTK-104 turbine compressor rotor has been measured experimentally at an enterprise. Figure 4 shows the results distribution chart. Regulation boundaries are defined according to Technical Guides 108.022-105-77 of the Russian Federation. It follows thence that fourth stage blades without any internal defects will have resonant frequencies within 334-345 Hz. 


\section{Conclusion}

Blade operation capacity analysis method will allow us to reduce the number of environmentally dangerous experiments, such as penetrant inspection, magnetic particle test (MPT), etching. The advantages of this control method are the following:

1) high sensitivity;

2) easy process engineering

3) no significant financial costs;

4) ecological safety;

5) perfect flexibility for environmental test

6) results visibility наглядность результатов.

As a result of our research we defined the areas of natural vibration frequency, when the blade is surely in operating condition. The experiment showed that the natural vibration frequency analysis allows to see exactly if there are any defects or breaks of blades.

\section{References}

1. Asgarshamsi, A., Hajilouy-Benisi, A., Assempour, A., Pourfarzaneh, H. (2017). Multipoint optimization of lean and sweep angles for stator and rotor blades of an axial turbine. Iranian Journal of Science and Technology - Transactions of Mechanical Engineering, 41(1), pp. 35-47.

2. Dong, Y. W., Li, X. L., Zhao, Q., Yang, J., Dao, M. (2017). Modeling of shrinkage during investment casting of thin-walled hollow turbine blades. Journal of Materials Processing Technology, 244, pp. 190-203.

3. Emelyanov, I. P., Ageev, E. V. (2015). Balancing features of car engine turbine compressors. International Journal of Applied Engineering Research, 10(24), pp. 45003-45006.

4. Klochkov, Y., Gazizulina, A. (2016). Application of the method of performance evaluation of the production proceb design using abociative design. Key Engineering Materials, 684, pp. 448-452.

5. Klochkov, Y., Gazizulina, A. (2016). Improvement of methodology of evaluation of efficiency of the etallurgical complex procebes development. Key Engineering Materials, 684, pp. 453-460.

6. Lang, G., Lin, J., Liao, Y., Zhao, M. (2017). Impact of system anisotropy on vibration reduction of rotating machinery and its evaluation method. Mechanical Systems and Signal Processing, 93, pp. 299-311.

7. Müller-Vahl, H. F., Pechlivanoglou, G., Nayeri, C. N., Paschereit, C. O., Greenblatt, D. (2017). Matched pitch rate extensions to dynamic stall on rotor blades. Renewable Energy, 105, pp. 505-519.

8. Payne, G. S., Stallard, T., Martinez, R. (2017). Design and manufacture of a bed supported tidal turbine model for blade and shaft load measurement in turbulent flow and waves. Renewable Energy, 107, pp. 312-326.

9. Sandberg, D., Mansour, R., Olsson, M. (2017). Fatigue probability assessment including aleatory and epistemic uncertainty with application to gas turbine compressor blades. International Journal of Fatigue, 95, pp. 132-142.

10. Swamy, M., Singh, K., Pavan, A. H. V., Antony Harison, M. C., Jayaraman, G. (2016). Failure Investigation of Frame 6FA Gas Turbine Compressor Blades. Transactions of the Indian Institute of Metals, 69(2), pp. 647-651.

11. Tiralap, A., Tan, C. S., Donahoo, E., Montgomery, M., Cornelius, C. (2017). Effects of rotor tip blade loading variation on compressor stage performance. Journal of Turbomachinery, 139(5),051006. 
12. Wood, D. H., Okulov, V. L. (2017). Nonlinear blade element-momentum analysis of Betz-Goldstein rotors. Renewable Energy, 107, pp. 542-549.

13. Xie, F., Ma, H., Cui, C., Wen, B. (2017). Vibration response comparison of twisted shrouded blades using different impact models. Journal of Sound and Vibration, 397, pp. 171-191.

14. Zhao, F., Smith, N., Vahdati, M. (2017). A simple model for identifying the flutter bite of fan blades. Journal of Turbomachinery, 139(7), 071003.

15. Zhao, Z., Fu, Y., Liu, X., Xu, J., Wang, J., Mao, S. (2017). Measurement-based geometric reconstruction for milling turbine blade using free-form deformation. Measurement: Journal of the International Measurement Confederation, 101, pp. 19-27.

16. Zvonov, S., Klochkov, Y. (2016). Computer-aided modelling of a latch die cutting in Deform -2D software system. Key Engineering Materials, 685, pp. 811-815.

17. Polyakova, M.A., Rubin, G.S., Gun, G.S., Danilova, Y.V. (2016). New approach to development methodology of requirements of standards for metal products. CIS Iron and Steel Review, 12, pp. 45-49.

18. Rubin, G.S., Polyakova, M.A., Chukin, M.V., Gun, G.S. (2013). Document Protypology: A new stage in the standardization of metal products. Steel in Translation, 43 (10), pp. 666-669. 